\title{
Regiocontroll synthesis cellulose-graft-polycaprolactone copolymer (2,3-di-O-PCL-cellulose) by a new route
}

\author{
K. L. Wang, N. Jiang, B. B. He ${ }^{*}$, D. X. Kang \\ College of Chemistry, Sichuan University, 610064 Chengdu, China
}

Received 6 May 2017; accepted in revised form 17 July 2017

\begin{abstract}
A new and convenient route to the regiocontrolled synthesis of a cellulose-based derivate copolymer (2,3-di-O-polycaprolactone-cellulose) grafting $\varepsilon$-caprolactone ( $\varepsilon$-CL) from $\alpha$-cellulose, cellulose-graft-polycaprolactone (cellulose-g-PCL), by a classical ring-opening polymerization (ROP) reaction, using stannous octoate $\left(\mathrm{Sn}(\mathrm{Oct})_{2}\right)$ as catalyst, in $68 \%$ concentration of zinc chloride aqueous solution at $120^{\circ} \mathrm{C}$ was presented. By controlling the hydroxyl of cellulose/ $/$-CL, catalyst/monomer ratio and the reaction time, the molecular architecture of the copolymers can be altered. The solubility of cellulose in zinc chloride aqueous was indicated by UV/VIS spectrometer and rheological measurements. The structures and thermal properties of cellulose- $g$-polycaprolactone copolymers were characterized using Fourier Transform Infrared (FT-IR), Proton Nuclear Magnetic Resonance Spectroscopy ( ${ }^{1} \mathrm{H}$ NMR), X-ray Diffraction (XRD), Thermogravimetric Analysis (TGA), Differential Scanning Calorimetry (DSC) and Inductively Coupled Plasma Optical Emission Spectrometry (ICP-OES). The interesting results confirm that zinc chloride solution can break the intra-molecular hydrogen bonds of cellulose selectively (not only $\mathrm{O}^{3} \mathrm{H}^{\cdots} \mathrm{O}^{5}$, but also $\left.\mathrm{O}^{2} \mathrm{H}^{\cdots} \mathrm{O}^{6}\right)$, and has no effect on the inter-molecular hydrogen bonds $\left(\mathrm{O}^{6} \mathrm{H}^{\cdots} \mathrm{O}^{3}\right)$. And the grafting reactivity of hydroxyl on cellulose is $\mathrm{C}^{2}-\mathrm{OH}>\mathrm{C}^{3}-\mathrm{OH} \gg \mathrm{C}^{6}-\mathrm{OH}$ in zinc chloride solution, and this is clearly different from other researches. Most importantly, this work confirms that the method to regiocontrolled synthesis cellulose-based derivative polymers by regiobreaking hydrogen bonds is feasible. It is strongly believed that the new discovery may give a novel, environmental, simple and inexpensive method to modify cellulose chemically with various side chains grafted on a given hydroxyl, through liberating hydroxyl as reactive group from hydrogen bonds broken selectively by different solvents.
\end{abstract}

Keywords: polymer synthesis, regiocontrolled synthesis polymers, cellulose-based derivation, zinc chloride aqueous, hydrogen bonds broken selectively

\section{Introduction}

It is well-known that lignocellulose is an almost inexhaustible and ubiquitous organic polymer material with fascinating structure and properties. Cellulose, a macromolecular polysaccharide composed by nonbranched $\beta-1,4$ linked d-glucose bonds (anhydroglucose unit, AGU), has been a promising and important source of renewable energy [1-4]. As a kind of common chemical raw material, cellulose has been used for about 150 years. Additionally there are several commercial cellulose-based derivative polymers that have been compounded such as acetate-, acetate butyrate-, or methyl-, carboxymethyl-, ethyl-, hydroxyethyl-, etc. Recently, cellulose derivatives are drawing an increasing attention due to their great potential as new recyclable thermoplastic materials, such as graft lactone and lactide grafted cellulose $[5,6]$. But unfortunately, these traditional cellulose products are with grafting monomer groups on hydroxyls groups at the $\mathrm{C}^{2}-\mathrm{C}^{3}$ - and $\mathrm{C}^{6}$ atoms on $\mathrm{AUG}$, in general, with combinations of only one kind functional group. Properties of the cellulose derivatives are determined primarily by the type of functional group. As a result, varieties and functions of cellulose-based production are few and single. 
Many attempts have been made to create new cellulose derivative materials with combinations of various functional groups. Selective polysaccharide functionalization is of importance in molecular and supramolecular structure design and the development of new products and properties [7]. In the case of cellulose, the examples of regioselective functionalization described 2,3-di-O-methyl- [8, 9], 2,6-di-Othexyldimethylsilyl- [10], 2,6-di-O-acetyl-3-O-methyl cellulose [11] and so on. In previous literatures, the protection/deprotection procedure is known as an example of the protective group technique in polysaccharide chemistry and as a possibility of controlling subsequent reactions such as etherization and esterification [7-12]. Protective groups were used in the selective protection of the secondary side of the cellulose. Mainly the methoxytrityl group and hexyldimethylsilyl group were utilized to protect the 6-O position. In this way, a great number of products with grafting monomer groups in the 2-O and/or 3-O position are available [13]. But the method is complex and the reaction conditions are demanding.

Because of the multiple hydroxyl groups on cellulose form intra- and inter-molecular hydrogen bonds, holding the chains together side-by-side firmly, the cohesion among cellulose chains makes it extremely insoluble in water and common organic solvents [14]. And the accessibility of other monomers to the inner core of the cellulose fibrils is quite restricted, the hydrogen bonds are the equal of self-protection system for hydroxyl groups. So the dissolution of cellulose is necessary. Until now, the methods to dissolve cellulose include the traditional solution system such as $\left[\mathrm{Cu}\left(\mathrm{NH}_{3}\right)_{4}\right](\mathrm{OH})_{2}$ (copper ammonia), and other typically investigated solvents like lithium chloride/ $N, N$-dimethylacetamide ( $\mathrm{LiCl} / \mathrm{DMA}$ ), tetrabutylammonium fluoride trihydrate/dimethyl sulfoxide [15, 16], as well as widely reported ionic liquids [17-19]. The solution systems can break the hydrogen bonds of cellulose than lead to the dissolution.

Based on this feature, a method to the regiocontrolled synthesis of cellulose-based derivative polymers by regiobreaking hydrogen bonds is proposed. Using specific solvent damage the hydrogen bond of $\mathrm{C}^{\mathrm{n}}-\mathrm{OH}$ directionally, $-\mathrm{OH}$ on $\mathrm{C}^{\mathrm{n}}-$ will be activated, in the meantime the rest of hydroxyl groups are still in a protected state, then chemical modification was made, so the regiocontrolled synthesis cellulose derivatives can be realized, eventually implementing the controlled synthesis of cellulose derivatives. The procedures of protecting hydroxyl groups regioselectively by introducing protective groups and the deprotection can be skipped. A careful check has shown that this method has not been tried by other researchers before [7-13].

The aim of the present paper is to research the feasibility of this method. So a new kind of cellulose solvent, zinc chloride aqueous solution $\left(\mathrm{ZnCl}_{2}\right)$ has been utilized. Therein, only $64-72 \%$ by weight zinc chloride in water can effectively dissolve cellulose. And zinc chloride solution can break the intra-molecular hydrogen bonds $\left(\mathrm{O}^{3} \mathrm{H} \cdots \mathrm{O}^{5}\right)$ of cellulose selectively, but has no effect on the inter-molecular hydrogen bonds [26]. Zinc chloride is a kind of recyclable, low toxicity, environmentally friendly and inexpensive common industrial salt [27]. So it is 'green' compared with other solvents. Additinally zinc chloride aqueous solution is acidic, and acidic system is beneficial to synthesize cellulose ester. So $\varepsilon$-caprolactone ( $\varepsilon-\mathrm{CL})$, a frequently-used monomer be applied to the esterification reaction of cellulose and also can mingle with water system, is chosen. In previous studies, various modified polymers have been synthesized from cellulose or cellulose derivatives by a ring-opening polymerization (ROP) reaction in ionic liquids [20-25].

In the present study, in order to find out whether this method, i.e. the regiocontrolled synthesisof cellulose-based derivative polymers by regiobreaking hydrogen bonds, with stannous octoate $\left(\mathrm{Sn}(\mathrm{Oct})_{2}\right)$ as catalyst is feasible, cellulose- $g$-polycaprolactone (cellulose-g-PCL) copolymers (2,3-di-O-PCL-cellulose) were prepared by classical ring-opening polymerization (ROP) grafting reaction of cellulose with $\varepsilon$-caprolactone ( $\varepsilon$-CL) in $68 \%$ zinc chloride solution. Finally the mechanism of $\left[\mathrm{Zn}\left(\mathrm{H}_{2} \mathrm{O}\right)_{4}\right]^{2+}$ effect on structures of cellulose copolymers were discussed.

\section{Experimental}

\subsection{Materials}

The cellulose ( $\alpha$-cellulose) used had a degree of polymerization (DP) of 332 determined according to GBT 5888-1986 applying copper(II)-ethylenediamine (Cuen) as solvent. The $\alpha$-cellulose, $\varepsilon$-caprolactone with a purity of $99.5 \%$ and $\mathrm{Sn}(\mathrm{Oct})_{2}$ with a purity of 99.5\% was purchased from Shanghai Macklin Biochemical Co., Ltd. Copper(II)-ethylenediamine (Cuen) complex with $1.0 \mathrm{M}$ solution in $\mathrm{H}_{2} \mathrm{O}$ was provided by J\&K Chemical Co., Ltd. Zinc chloride with a purity of more than $98.0 \%$ was provided by Chengdu Kelon 
Chemical Industry Co., Ltd. The cellulose was dried under vacuum at $70^{\circ} \mathrm{C}$ for $24 \mathrm{~h}$ before used. Toluene, ethanol, nitric acid and perchloric acid were analytical reagents without further purification.

\subsection{Dissolution of cellulose}

In this dissolution experiment, cellulose was added into a $250 \mathrm{~mL}$ three-necked flask which contained $38 \mathrm{~g}$ of $54 \%$ zinc chloride solution previously. Then the flask was immersed in an oil bath (DF-101S, Gongyi Yingyu Instrument Factory), and the temperature was controlled at $65 \pm 0.5^{\circ} \mathrm{C}$. The mixture was heated and mixed rapidly at the given temperature to make sure cellulose dissoved in the solution uniformly. Then $12 \mathrm{~g}$ zinc chloride was added, and kept agitating moderately under dry nitrogen atmosphere for $2 \mathrm{~h}$ to insure that the system was mixed thoroughly. Therein, the flask was sealed with glass stoppers. The solubility was monitored using percent transmittance by ultraviolet spectrophotometer (TU-190138 UV/VIS spectrometer, $200-900 \mathrm{~nm}$ ). The viscosity of the system was measured with a NXS-11A rotary viscometer (China) at $65^{\circ} \mathrm{C}$.

\subsection{Synthesis of cellulose-g-PCL copolymers}

Cellulose-g-PCL copolymers were synthesized by the grafting reaction of cellulose with $\varepsilon-C L$ in zinc chloride solution with $\mathrm{Sn}(\mathrm{Oct})_{2}$ as catalyst at $120^{\circ} \mathrm{C}$ via ring opening polymerization reaction. The investigated factors affecting the grafting reaction included the reaction time, molar ratios of $\varepsilon$ $\mathrm{CL} /$ anhydroglucose unit (AGU) and $\mathrm{Sn}(\mathrm{Oct})_{2} / \varepsilon-\mathrm{CL}$ monomer.

A $250 \mathrm{~mL}$ three-necked flask was put into an oil bath, initially $4 \mathrm{~g}$ cellulose and $22.4 \mathrm{~g} \varepsilon$-CL were added and mixed by mechanical stirring at $80^{\circ} \mathrm{C}$ for $5 \mathrm{~min}$. Then decanted $50 \mathrm{~g} 68 \%$ zinc chloride solution and $1.6 \mathrm{~g} \mathrm{Sn}(\mathrm{Oct})_{2}$ were mixed with vigorous stirring to make sure that all components dispersed uniformly. Subsequently the reaction was carried at $120^{\circ} \mathrm{C}$ under nitrogen atmosphere with mechanical stirring for $24 \mathrm{~h}$. When the temperature was higher than $120^{\circ} \mathrm{C}$, cellulose would degrade, however, lower temperature resulted in the decrease of reactivity. Following the completion of grafting reaction, the reaction system was cooled to room temperature, the resultant polymer was precipitated by deionized water, solidliquid separated through air pump filtration. The solids obtained were washed with water three times to make sure zinc chloride was removed completely and dried in a vacuum oven at $70^{\circ} \mathrm{C}$. The crude product was finally purified with solvent (toluene: ethanol $=1: 2$ ), extracted for $12 \mathrm{~h}$ using a Soxhlet extractor, to remove unreacted caprolactone and polycaprolactone homopolymer formed during polymerization. The pure sample (cellulose-g-PCL) was dried at $70^{\circ} \mathrm{C}$ for $24 \mathrm{~h}$ in a vacuum drying oven until reaching a constant weight.

\subsection{Characterization of cellulose-g-PCL copolymers}

\subsubsection{Attenuated total internal reflectance}

\section{Fourier transform infrared (ATR FT-IR)}

ATR FT-IR spectra of samples were recorded on a Nicolet-Nexus 670 infrared spectrophotometer (Nicolet, USA) in a spectral range of $400-4000 \mathrm{~cm}^{-1}$ at a resolution of $4 \mathrm{~cm}^{-1}$. The scan speed was $0.2 \mathrm{~cm} / \mathrm{s}$ and 10 scans were taken per sample.

\subsubsection{Nuclear magnetic resonance spectroscopy (NMR)}

${ }^{1} \mathrm{H}$ NMR spectra of the synthesized cellulose- $g$-PCL copolymers were obtained from a Bruker AVANCE AV II-400 MHz spectrometer (Switzerland) using DMSO- $d_{6}$ as solvent, and tetramethysilane (TMS) as an internal standard.

The molecular factors of the graft copolymers including $\mathrm{DP}_{\mathrm{PCL}}$ (average degree of polymerization of

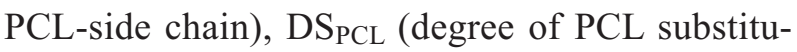
tion), $\mathrm{MS}_{\mathrm{PCL}}$ (an average number of introduced CL units per anhydroglucose of cellulose) and $\mathrm{W}_{\mathrm{PCL}}$ (weight content of PCL side chains) were estimated by the calculations with the intensity of peak corresponding signals in ${ }^{1} \mathrm{H}$ NMR spectra according to the following Equations (1), (2), (3) and (4) respectively [22]. The molecular weights of the $\varepsilon-C L$ monomer and the molecular weight of cellulose repeating unit are $114 \mathrm{~g} / \mathrm{mol}$ and $162 \mathrm{~g} / \mathrm{mol}$ respectively; $I a, I a^{\prime}$ and $I_{\mathrm{H}_{4}}$ in the equations are peak intensities of $-\mathrm{COCH}_{2}-\left(a\right.$, repeating unit), $-\mathrm{COCH}_{2}-\left(a^{\prime}\right.$, end unit) and $\mathrm{H}_{4}$ on copolymers respectively:

$$
\begin{aligned}
& \mathrm{MS}_{\mathrm{PCL}}=\frac{\mathrm{CL}}{\mathrm{AGU}}=\frac{\frac{I\left(a+a^{\prime}\right)}{2}}{I_{\mathrm{H}^{4}}} \\
& \mathrm{DS}_{\mathrm{PCL}}=\frac{\text { terminal CL }}{\mathrm{AGU}}=\frac{\frac{I a^{\prime}}{2}}{I_{\mathrm{H}^{4}}} \\
& \mathrm{DP}_{\mathrm{PCL}}=\frac{\mathrm{MS}_{\mathrm{PCL}}}{\mathrm{DS}_{\mathrm{PCL}}}=1+\frac{I a}{I a^{\prime}}
\end{aligned}
$$


$\mathrm{W}_{\mathrm{PCL}}=\frac{114 \mathrm{MS}_{\mathrm{PCL}}}{162+114 \mathrm{MS}_{\mathrm{PCL}}} \cdot 100 \%$

\subsubsection{X-ray diffraction (XRD)}

The X-ray powder diffraction patterns were collected in a SHIMADZU Lab X-ray diffractometer (Japan) in Theta-2Theta configuration, in which the secondary monochromatic $\mathrm{Cu}$ radiation was generated at $40 \mathrm{kV}$ and $30 \mathrm{~mA}$. Data were collected from 5 to $60^{\circ}$ at a speed of $4 \% \mathrm{~min}$ and a step size of $0.02^{\circ}$ at room temperature.

\subsubsection{Thermogravimetric analysis (TGA)}

The TGA of samples was carried on a METTLER TOLEDO TGA 2 thermogravimetric analyzer (Switzerland) with a heating rate of $10^{\circ} \mathrm{C} / \mathrm{min}$ from 25 to $600{ }^{\circ} \mathrm{C}$ under nitrogen atmosphere.

\subsubsection{Differential scanning calorimetry (DSC)}

The DSC of the synthesized cellulose- $g$-PCL copolymers were obtained from a DSC Q20 of TA Instruments (USA). Each sample was heated from 25 to $200^{\circ} \mathrm{C}$ at a scanning rate of $10^{\circ} \mathrm{C} / \mathrm{min}$.

\subsubsection{Inductively coupled plasma optical emission spectrometry (ICP-OES)}

The remaining $\mathrm{Zn}$ and $\mathrm{Sn}$ species in the purified cellulose- $g$-PCL samples were analyzed by Inductively Coupled Plasma Optical Emission Spectrometry (ICPOES) (PQ-EXCELL ICP-MS, Germany). For element determination, around $0.02 \mathrm{~g}$ of sample were digested with $5 \mathrm{~mL} \mathrm{HNO}_{3}$ and $2.5 \mathrm{~mL} \mathrm{HClO}_{4}$ perchloric acid, and fumed upon heating, the remainder was dissolved in $5 \mathrm{~mL}$ aqua regia, diluted with water to $100 \mathrm{~mL}$ finally. At least three blanks were subjected to a similar sample preparation and analytical procedure.

\section{Results and discussion}

\subsection{Dissolution of cellulose}

According to the results of the dissolution experiment of cellulose shown in Figure 1, as the content of cellulose increases continuously, the viscosity goes up. These systems with $1-4 \mathrm{~g}$ cellulose in $50 \mathrm{~g}$ $68 \%$ zinc chloride solution are transparent and show acceptable viscosity, but $5 \mathrm{~g}$ cellulose makes this system much too viscous and opaque.

Possible reason for the results is the molar ratio of $\mathrm{Zn}^{2+}: \mathrm{H}_{2} \mathrm{O}$ is just $1: 4$ in $65 \%$ zinc chloride solution,

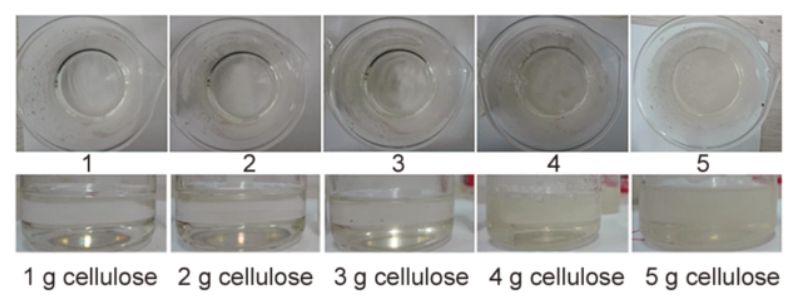

Figure 1. Photographs of cellulose with various weights in 50 g $68 \%$ zinc chloride solution

theoretically, the amount of electrons on $3 \mathrm{~d}$ electronic orbit of $\mathrm{Zn}^{2+}$ is $10,4 \mathrm{~s}$ and $4 \mathrm{p}$ electronic orbits via $\mathrm{sp}^{3}$ hybridized function to form four $\mathrm{sp}^{3}$ hybrid orbits, and each $\mathrm{sp}^{3}$ hybrid orbit can accept a lone pair electrons on oxygen atom of $\mathrm{H}_{2} \mathrm{O}$ to generate a complex $\left[\mathrm{Zn}\left(\mathrm{H}_{2} \mathrm{O}\right)_{4}\right]^{2+}$ as shown in Figure 2. But the purity of zinc chloride used by us was less than $100 \%$ and zinc chloride solid can absorb water easily, so the concentration of solutions needs to be higher than $65 \%$ slightly rise to $68 \%$. The complex $\left[\mathrm{Zn}\left(\mathrm{H}_{2} \mathrm{O}\right)_{4}\right]^{2+}$ has two positive charges, so there exists two $4 \mathrm{~d}$ activated electronic orbits in its outermost shell, two pairs of isolated charges on oxygen atom of hydroxyl on cellulose can be accepted. This may destroy the hydrogen bonds of cellulose, to ensure that cellulose is able to dissolve in $68 \%$ zinc chloride solution.

If the molar ratio of $\mathrm{Zn}^{2+}: \mathrm{H}_{2} \mathrm{O}$ is just less than $1 / 4$, the activated orbits of $\mathrm{Zn}^{2+}$ will be occupied by the extra water molecules, zinc chloride solution will not be able to dissolve cellulose. Meanwhile, when the molar ratio of $\mathrm{Zn}^{2+}: \mathrm{H}_{2} \mathrm{O}$ is larger than $1 / 4,\left[\mathrm{Zn}\left(\mathrm{H}_{2} \mathrm{O}\right)_{\mathrm{n}}\right]^{2+}$ $(n<4)$ will not only disrupt hydrogen bonds but also crosslink free hydroxyl groups, resulting in the formation of subsequent gelation [28].

The solubility of cellulose in zinc chloride solutions was indicated using percent transmittance probed by the UV-vis absorption studies (Figure 3). As we know, the percent transmittance of the various cellulose/zinc chloride solutions decreases with increasing concentration of cellulose, and the exact figures of the solutions $(a, b, c)$ in visible light spectrum

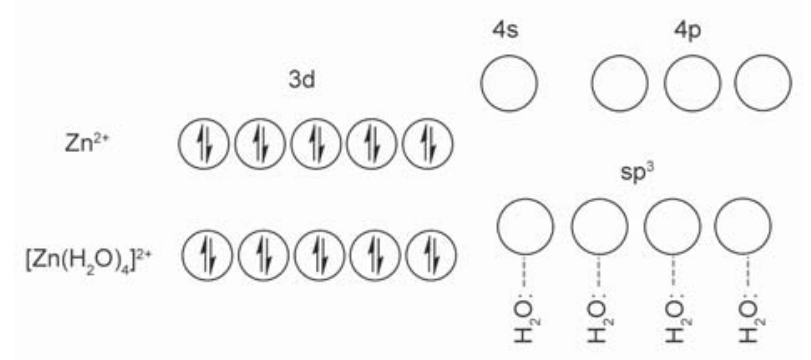

Figure 2. Graph of hybrid orbits of $\left[\mathrm{Zn}\left(\mathrm{H}_{2} \mathrm{O}\right)_{4}\right]^{2+}$ 


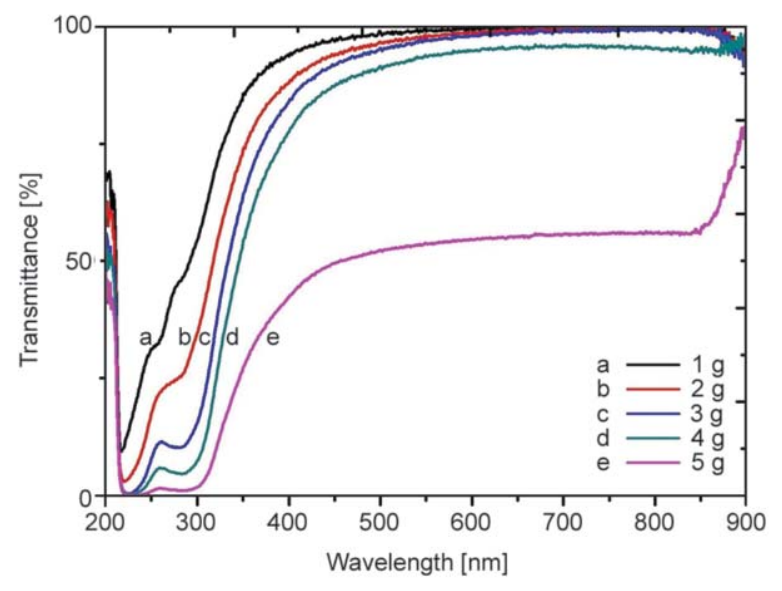

Figure 3. The percent transmittance of various cellulose/zinc chloride solutions

( $400-800 \mathrm{~nm}$ ) is up to $100 \%$, curve $\mathrm{d}$ is above $93 \%$, but the transmittance of curve e quickly decreases to approximately $50 \%$, which is identical with Figure 1 . So the dissolution system of this experiment, the maximum solubility of cellulose is $7.4 \%$. Therefore, the optimum system (4 $\mathrm{g} \alpha$-cellulose in $50 \mathrm{~g}$ $68 \%$ zinc chloride solution) was designated as the experiment condition to synthesize cellulose- $g$-PCL. Figure 4 shows the changes of viscosity values, $\eta$, as a function of angular frequency for the cellulose/ zinc chloride solutions with different concentrations at $65^{\circ} \mathrm{C}$. The most prominent feature is that the viscosity values for all blends decrease with increasing shear rate, suggesting a shear-thinning behavior. So these solutions are pseudoplastic fluids. The decrease of $\eta$ values indicates the formation and enhancement of the aligned or oriented cellulose chains. Another easily observable phenomenon is that the $\eta$ values of the cellulose/zinc chloride solutions increase with increasing the content of cellulose. And then values of systems with $1-4 \mathrm{~g}$ cellulose in $50 \mathrm{~g} 68 \%$ zinc chloride solution are little and approximate relatively, but the viscosity of $5 \mathrm{~g}$ solid solute system is much higher than that of the others, which is in agreement with

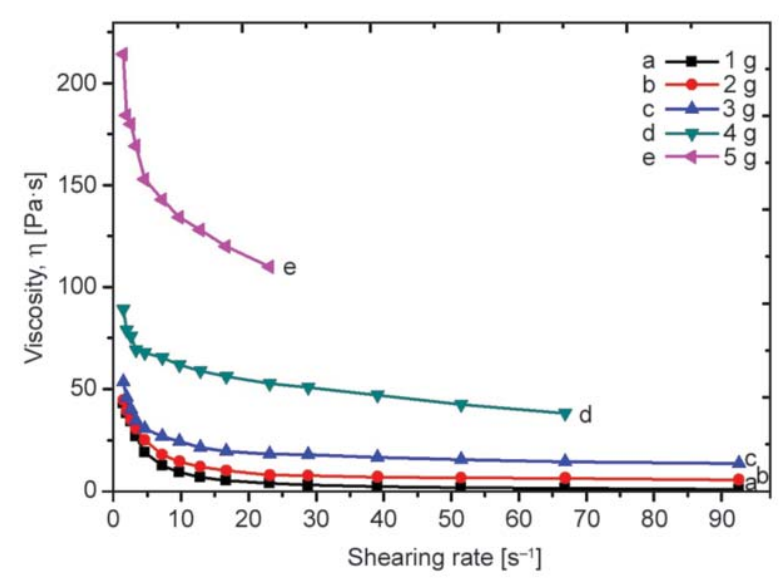

Figure 4. Shear flow curves for the cellulose /zinc chloride solutions with different concentrations at $65^{\circ} \mathrm{C}$

above results of the cellulose dissolution experiment shown in Figure 1 and with the transmittance values shown in Figure 3.

\subsection{Synthesis and characterization of cellulose-g-PCL copolymers}

Cellulose- $g$-PCL copolymers were prepared by graft copolymerization of $\varepsilon$-CL with $4 \mathrm{~g}$ cellulose using $\mathrm{Sn}(\mathrm{Oct})_{2}$ as catalyst in $50 \mathrm{~g} 68 \%$ zinc chloride solution. The ${ }^{1} \mathrm{H}$ NMR data were used for the determination of $\mathrm{DP}_{\mathrm{PCL}}, \mathrm{DS}_{\mathrm{PCL}}, \mathrm{MS}_{\mathrm{PCL}}$ and $\mathrm{W}_{\mathrm{PCL}}$. The $68 \%$ zinc chloride solution was employed to destroy the hydrogen bonds of cellulose, liberate and activate the hydroxyl, disperse cellulose and $\varepsilon$-CL monomers and provide lower solution viscosity for the reaction system. $\mathrm{Sn}(\mathrm{Oct})_{2}$ was applied to catalyze the ROP of the $\varepsilon$-CL monomers grafted from cellulose. The grafting reaction is most commonly performed in the presence of a metal-based catalyst for ROP of $\varepsilon-C L$ or lactone [6] In particular, whenpolymerization experiments without $\mathrm{ZnCl}_{2}$ were implemented, using $4 \mathrm{~g}$ cellulose and $\mathrm{Sn}(\mathrm{Oct})_{2}$ as catalyst in $50 \mathrm{~g}$ deionized water, after the reaction, the products cannot be dissolved in DMSO- $d_{6}$ completely, and the resulting

Table 1. Results of cellulose- $g$-PCL copolymers prepared by graft polymerization in zinc chloride solution at $120^{\circ} \mathrm{C}$

\begin{tabular}{|c|c|c|c|c|c|c|c|c|}
\hline Samples & $\begin{array}{c}\boldsymbol{\varepsilon}-\mathbf{C L} / \mathbf{A G U} \\
{[\mathbf{m o l} / \mathbf{m o l}]}\end{array}$ & $\begin{array}{c}\text { Sn(Oct) } \mathbf{2} / \mathbf{\varepsilon}-\mathbf{C L} \\
{[\mathbf{m o l} / \mathbf{m o l}]}\end{array}$ & $\begin{array}{c}\text { Reaction time } \\
{[\mathbf{h}]}\end{array}$ & $\mathbf{M S S C L}_{\mathbf{P C L}}$ & $\mathbf{D S S C L}_{\mathbf{P C L}}$ & $\mathbf{D P}_{\mathbf{P C L}}$ & $\begin{array}{c}\mathbf{W}_{\text {PCL }} \\
{[\mathbf{\%}]}\end{array}$ & $\begin{array}{c}\text { Yields of products } \\
\text { [g] }\end{array}$ \\
\hline 1 & $8 / 1$ & $1 / 100$ & 6 & 0.77 & 0.32 & 2.35 & 35 & 2.1538 \\
\hline 2 & $8 / 1$ & $1 / 100$ & 12 & 1.12 & 0.45 & 2.49 & 44 & 2.9224 \\
\hline 3 & $8 / 1$ & $1 / 100$ & 24 & 1.54 & 0.62 & 2.48 & 52 & 3.4442 \\
\hline 4 & $8 / 1$ & $2 / 100$ & 24 & 4.03 & 1.38 & 2.92 & 74 & 5.2352 \\
\hline 5 & $8 / 1$ & $3 / 100$ & 24 & 3.02 & 1.13 & 2.67 & 68 & 4.5826 \\
\hline 6 & $4 / 1$ & $2 / 100$ & 24 & 0.56 & 0.26 & 2.15 & 28 & 1.7346 \\
\hline 7 & $12 / 1$ & $2 / 100$ & 24 & 6.47 & 1.92 & 3.37 & 82 & 6.3247 \\
\hline
\end{tabular}


FT-IR spectra showed that the product is still cellulose.

The results are summarized in Table 1. Samples 1-3 were designed with different reaction times at fixed molar ratios $\mathrm{Sn}(\mathrm{Oct})_{2} / \varepsilon-\mathrm{CL}$ and $\varepsilon$-CL/AGU. With the extension of reaction time, all the $\mathrm{DP}_{\mathrm{PCL}}, \mathrm{DS}_{\mathrm{PCL}}$, $\mathrm{MS}_{\mathrm{PCL}}$ and $\mathrm{W}_{\mathrm{PCL}}$ increased slowly. But if increasing the dosage of catalyst from 1 to $2 \%$, such as Sample 3 and Sample 4, all the DPPCL, $\mathrm{DS}_{\mathrm{PCL}}, \mathrm{MS}_{\mathrm{PCL}}$ and $\mathrm{W}_{\mathrm{PCL}}$ increased greatly because the reaction sites had not been saturated. When the molar ratio of $\mathrm{Sn}(\mathrm{Oct})_{2} /$ $\varepsilon$-CL increased further, the grafting content of PCL decreased, displayed by Sample 5, for the reason that the increase of the catalyst enhanced the competitive homo-polymerization of $\varepsilon$-CL, production of PCL would increase. Then the influence of the molar ratio of $\varepsilon$-CL/AGU (Samples 4, 6, 7) was investigated. As the ratio of $\varepsilon-\mathrm{CL} / \mathrm{AGU}$ increased, $\mathrm{DP}_{\mathrm{PCL}}, \mathrm{DS}_{\mathrm{PCL}}$, $\mathrm{MS}_{\mathrm{PCL}}$ and $\mathrm{W}_{\mathrm{PCL}}$ reached their maximum. Therefore, the composition of cellulose- $g$-PCL copolymers can be regulated by the molar ratio of $\varepsilon$-CL/AGU. The MS $_{\text {PCL }}$ of sample 7 went up to 6.47 , approximately equal to that reported in many previous literatures $[22,23]$. Several attempts to gain sample with larger $\mathrm{MS}_{\mathrm{PCL}}$ failed, which could be attributed to the occurrence of transesterification reaction of PCL within the copolymer, which resulted in the increase of PCL homopolymer [25]. And the yields of the purified cellulose- $g$-PCLs were reported in Table 1. There are several sets of quantity less than $4 \mathrm{~g}$, and the yields of all samples are far below the total quantity of raw materials (cellulose add $\varepsilon-C L$ ), the probable reason may be that under heating in zinc chloride solution, cellulose is not stable, and is partially degraded. Meanwhile $\varepsilon$-CL also exhibits self-polymerization.

The FTIR spectra of cellulose and cellulose- $g$-PCL in a range of $4000-400 \mathrm{~cm}^{-1}$ were compared in Figure 5 . In the spectra of cellulose, absorption bands at $3351 \mathrm{~cm}^{-1}(\mathrm{O}-\mathrm{H}$ stretching vibration of hydroxyl on cellulose); $2899 \mathrm{~cm}^{-1}$ (C-H symmetric vibration of $-\mathrm{CH}-) ; 1429 \mathrm{~cm}^{-1}$ (C-H scissoring vibration); $1371 \mathrm{~cm}^{-1}(\mathrm{O}-\mathrm{H}$ in plane bending vibration); $1161 \mathrm{~cm}^{-1}$ (C1-O-C6 stretching vibration of anhydroglucose unit); $1110 \mathrm{~cm}^{-1}(\mathrm{C}-\mathrm{OH}$ stretching vibration of secondary hydroxyl $\mathrm{C}^{2}-\mathrm{O}^{2} \mathrm{H}$ and $\mathrm{C}^{3}-\mathrm{O}^{3} \mathrm{H}$ ); $1059 \mathrm{~cm}^{-1}(\mathrm{C}-\mathrm{OH}$ stretching vibration of primary alcohol $\left.\mathrm{C}^{6}-\mathrm{O}^{6} \mathrm{H}\right) ; 1639,898 \mathrm{~cm}^{-1}$ ( $\beta$-glucosidic linkages between sugar units in cellulose); $667 \mathrm{~cm}^{-1}$ (O-H bending vibration out the plane) are observed.

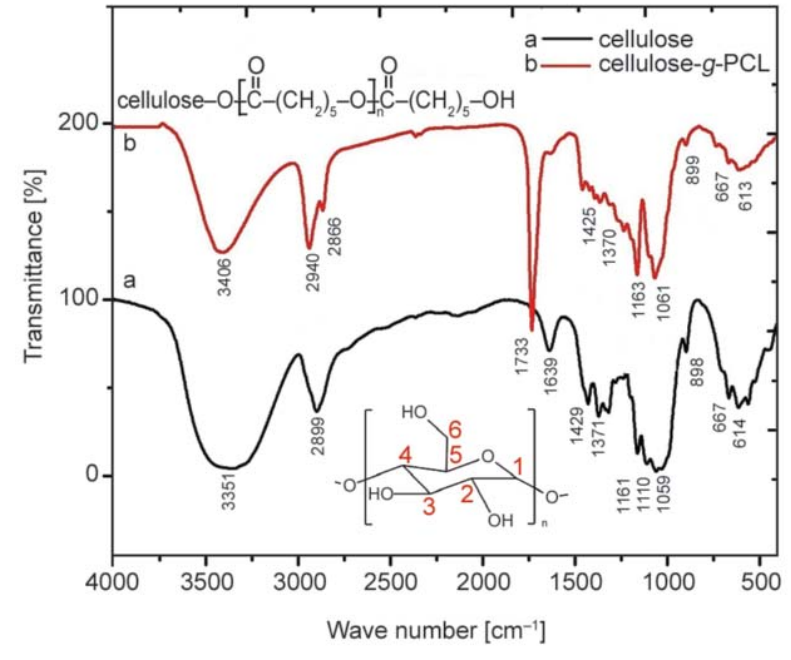

Figure 5. FT-IR spectra of cellulose (a) and cellulose- $g$-PCL copolymer Sample 4 (b)

In the case of cellulose-g-PCL, new peaks at $3406 \mathrm{~cm}^{-1}$ (O-H stretching vibration of unreacted hydroxyl of cellulose); $2940 \mathrm{~cm}^{-1}\left(-\mathrm{CH}_{2}-\right.$ antisymmetric stretching vibration); $2866 \mathrm{~cm}^{-1}\left(-\mathrm{CH}_{2}-\mathrm{sym}-\right.$ metric stretching vibration); $1733 \mathrm{~cm}^{-1} \quad(-\mathrm{C}=\mathrm{O}$ stretching vibration of ester group) are observed.

In the FT-IR spectra of cellulose-g-PCL Samples, a reduction of the intensity of $-\mathrm{OH}$ groups at 3200 to $3500 \mathrm{~cm}^{-1}$ is evident, indicating the conversion of $-\mathrm{OH}$ groups [30]. The increased intensity of the peaks corresponding to $\mathrm{C}-\mathrm{H}$ groups in $-\mathrm{CH}_{2}-$ and $-\mathrm{CH}-$ at 2800 to $2960 \mathrm{~cm}^{-1}$ and the presence of a peak at $1733 \mathrm{~cm}^{-1}(-\mathrm{C}=\mathrm{O})$ confirm the ring opening copolymerization of $\varepsilon$-caprolactone with cellulose.

Generally, it is clear that the reactivity of each hydroxyl on anhydroglucose unit of cellulose is different theoretically. In the esterification reaction, the reactivity of primary hydroxyl is higher than that of the secondary hydroxyl because of the steric hindrance of primary hydroxyl. And in the acidic medium, the reaction on the primary hydroxyl is even easier [35]. And a preferential reaction is at the $\mathrm{C}^{6}$ position of cellulose, and the order of reactivity is $\mathrm{C}^{6}-\mathrm{OH}>$ $\mathrm{C}^{3}-\mathrm{OH}>\mathrm{C}^{2}-\mathrm{OH}$ which is well consistent with the reported work for cellulose graft in ionic liquid [31, 32]. Interestingly, in the FT-IR spectra of cellulose- $g$-PCL absorption band $1067 \mathrm{~cm}^{-1}$ still exists except band $1110 \mathrm{~cm}^{-1}$, which indicates that the primary hydroxyl $\mathrm{C}^{6}-\mathrm{O}^{6} \mathrm{H}$ still exists largely, the secondary hydroxyls of $\mathrm{C}^{2}-\mathrm{O}^{2} \mathrm{H}$ and $\mathrm{C}^{3}-\mathrm{O}^{3} \mathrm{H}$ are reduced in number or disappear in cellulose-g-PCL. It manifests the graft reaction mainly occurred on the secondary hydroxyl, $\varepsilon$-CL did not react with hydroxyl groups on $\mathrm{C}^{6}$. 
The research of Qin Xu et al. reported the effect of $\mathrm{Zn}^{2+}$ ions on solubilizing cellulose via breaking or weaning $\mathrm{O}^{3} \mathrm{H} \cdots \mathrm{O}^{5}$ hydrogen bonds that were responsible for the tight and insoluble cellulose network structure [26]. So it was presumably due to the fact that only hydroxyl groups on $\mathrm{C}^{3}$ were activated by $\mathrm{Zn}^{2+}$ ions, $\varepsilon$-CL reacted with $\mathrm{C}^{3}-\mathrm{O}^{3} \mathrm{H}$ to weaken peaks of secondary hydroxyl and decrease the intensity of -OH groups. But after analyzing the ${ }^{1} \mathrm{H}$ NMR spectra of cellulose- $g$-PCL copolymers, more new conclusions may been drawn as shown in the following. ${ }^{1} \mathrm{H}$ NMR spectra of cellulose- $g$-PCL copolymer $\left(\mathrm{MS}_{\mathrm{PCL}}=4.03, \mathrm{DS}_{\mathrm{PCL}}=1.38\right)$ are shown in Figure 6. The methylene proton peaks of PCL can be observed at $\delta=1.29 \mathrm{ppm}\left(-\mathrm{CH}_{2}-1.53 \mathrm{ppm}\left(-\mathrm{COCH}_{2}-\right.\right.$, a, repeating unit), $2.28 \mathrm{ppm}\left(-\mathrm{COCH}_{2}-, \mathrm{a}^{\prime}\right.$, end unit), and 3.99 ppm $\left(-\mathrm{CH}_{2} \mathrm{O}-\right.$, e, repeating units) [29]. Of particular note is the peak of $-\mathrm{CH}_{2} \mathrm{OH}\left(\mathrm{e}^{\prime}\right.$, end unit) should appear at $\delta=3.37 \mathrm{ppm}$, but it is masked by the water peak $(\delta=3.27-3.45)$. These show that cellulose-graft-PCL copolymers were successfully synthesized. The resonance peaks derived from the protons of AGU of cellulose backbone appear at $\delta=$ 4.68, 3.54, 3.79, 3.05 ppm attributed by $\mathrm{H}^{1}, \mathrm{H}^{2,5,6}, \mathrm{H}^{3}$ and $\mathrm{H}^{4}$, respectively. Meanwhile, the signals at $\delta=$ $5.41 \mathrm{ppm}\left(\mathrm{O}^{6} \mathrm{H}\right)$, and $4.36 \mathrm{ppm}\left(\mathrm{O}^{3} \mathrm{H}\right)$ correspond to the protons of the residual hydroxyl groups of $\mathrm{AGU}$ [15]. There is no peak at $\delta=5.51 \mathrm{ppm}\left(\mathrm{O}^{2} \mathrm{H}\right)$, indicating no residual $\mathrm{O}^{2} \mathrm{H}$ on $\mathrm{AGU}$.

$$
I_{\mathrm{O}^{6} \mathrm{H}}=I_{\mathrm{H}^{1}} \approx I_{\mathrm{H}^{3}} \approx I_{\mathrm{H}^{4}} \approx \frac{1}{4} I_{\mathrm{H}^{2,5,6}}>I_{\mathrm{O}^{3} \mathrm{H}} \gg I_{\mathrm{O}^{2} \mathrm{H}}
$$

In order to compare the relationship of peak intensities corresponding to each proton on AGU is shown above. It manifests that $\mathrm{O}^{6} \mathrm{H}$ does not react with $\varepsilon$-CL,

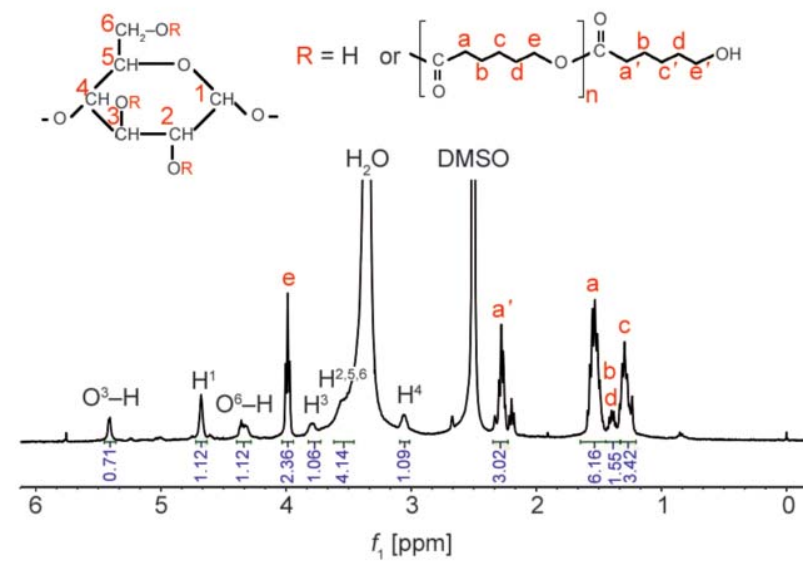

Figure 6. ${ }^{1} \mathrm{H}$ NMR spectrum of cellulose- $g$-PCL copolymer Sample 4
Table 2. Maximum degree of PCL substitution ( $\mathrm{DS}_{\max }$ ), grafting sites and regioselectivity between the previous examples and the $\mathrm{ZnCl}_{2}$ method developed in the present study

\begin{tabular}{|l|c|l|c|}
\hline \multicolumn{1}{|c|}{ Method } & DS $_{\max }$ & \multicolumn{1}{c|}{ Grafting sites } & Regioselectivity \\
\hline Lee et al. $[21]$ & 2.35 & $\mathrm{C}^{6}-, \mathrm{C}^{2}-, \mathrm{C}^{3}-$ & - \\
\hline Guo et al. $[23]$ & 2.41 & $\mathrm{C}^{6}-, \mathrm{C}^{2}-, \mathrm{C}^{3}-$ & - \\
\hline Yan et al. $[25]$ & 2.91 & $\mathrm{C}^{6}-, \mathrm{C}^{2}-, \mathrm{C}^{3}-$ & - \\
\hline Yan et al. [20] & 2.74 & $\mathrm{C}^{6}-, \mathrm{C}^{2}-, \mathrm{C}^{3}-$ & - \\
\hline $\mathrm{ZnCl}_{2}$ method & 1.92 & $\mathrm{C}^{2}-, \mathrm{C}^{3}-$ & + \\
\hline
\end{tabular}

+: Having regioselectivity; -: out of regioselectivity

hydrogen of $\mathrm{O}^{3} \mathrm{H}$ is replaced by carbonyl group sectionally and $\mathrm{O}^{2} \mathrm{H}$ converts into ester group completely. This conclusion is in agreement with above FTIR characterization in Figure 5.

Based on above analyses, it can be concluded that $\left[\mathrm{Zn}\left(\mathrm{H}_{2} \mathrm{O}\right)_{\mathrm{n}}\right]^{2+}$ not only breaks the $\mathrm{O}^{3} \mathrm{H} \cdots \mathrm{O}^{5}$ hydrogen bonds, but also the $\mathrm{O}^{2} \mathrm{H}^{\cdots} \mathrm{O}^{6}$ hydrogen bonds, and has no effect on the intermolecular hydrogen bonds of $\mathrm{O}^{6} \mathrm{H}^{\cdots} \mathrm{O}^{3}$. Furthermore the reaction activity of hydroxyl on cellulose is $\mathrm{C}^{2}-\mathrm{O}^{2} \mathrm{H}>\mathrm{C}^{3}-\mathrm{O}^{3} \mathrm{H} \gg$ $\mathrm{C}^{6}-\mathrm{O}^{6} \mathrm{H}$ in zinc chloride aqueous solution.

Table 2 shows the comparisons of the regioselectivity on the grafting reaction between the previous examples and the $\mathrm{ZnCl}_{2}$ method of our work. The grafting sites in previous examples all are $\mathrm{C}^{6}-, \mathrm{C}^{2}-$ and $\mathrm{C}^{3}$-, but the results of the $\mathrm{ZnCl}_{2}$ method indicate that there exists primary hydroxyl $\mathrm{C}^{6}-\mathrm{O}^{6} \mathrm{H}$ in cellulose-g-PCL with secondary hydroxyl of $\mathrm{C}^{2}-\mathrm{O}^{2} \mathrm{H}$ and $\mathrm{C}^{3}-\mathrm{O}^{3} \mathrm{H}$ being replaced by $\mathrm{PCL}$, grafting reaction mainly occurs on the $\mathrm{C}^{6}$ - hydroxyl, this method has regioselectivity.

\subsection{Crystalline and thermal properties of cellulose-g-PCL copolymers}

Figure 7 shows the XRD patterns of cellulose and cellulose- $g$-PCL copolymers with various PCL contents. Curve (a) shows a semi-crystalline character of cellulose-I with three main peaks located at $2 \theta=$ $15.232,22.671$, and $34.754^{\circ}$, corresponding to the

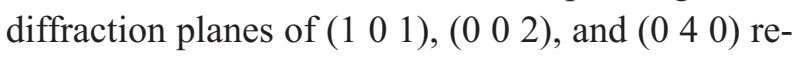
spectively $[33,34]$. While cellulose- $g$-PCL copolymers show the same diffraction peaks at $2 \theta=22.671$ and $34.160^{\circ}$ as the characteristic diffraction of cellulose, but the peak at $22.671^{\circ}$ becomes smaller, and the peak at $15.3^{\circ}$ disappeared, rather than appeared a new wide peak in other reports $[14,15]$.

These data suggest that the original crystalline structure of cellulose has not been destroyed completely, 


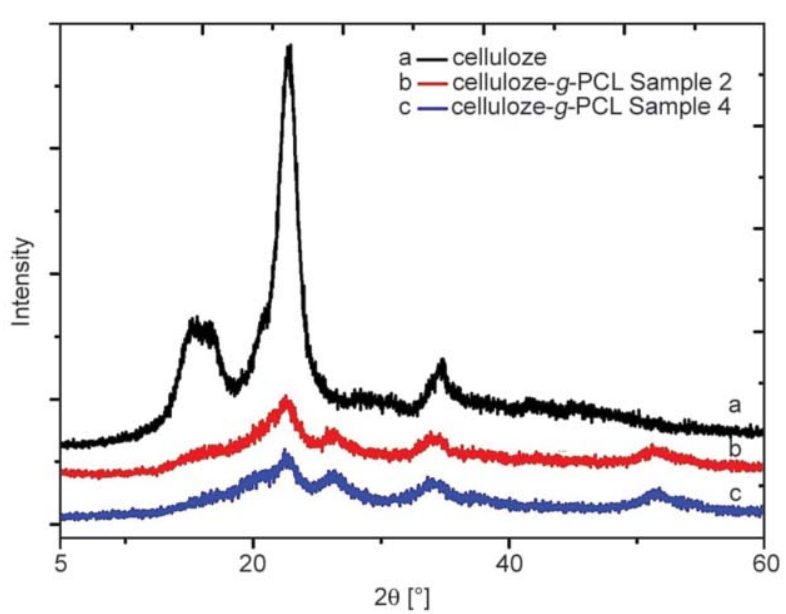

Figure 7. XRD spectra of cellulose (a), cellulose-g-PCL Sample 2 (b) and cellulose-g-PCL Sample 4 (c)

there still existed hydrogen bonding structures after introduction of PCL side chains. This result conforms to the above conclusion that zinc-aqueous cation only break intra-molecular hydrogen bonds, and has no effect on the inter-molecular hydrogen bonds. Meanwhile, a new small peak centered at $2 \theta=26.289^{\circ}$ appears in the diffraction patterns of copolymers, it may be ascribed to the interaction between PCL segments and cellulose backbone.

The thermal stabilities of cellulose and cellulose- $g$ PCL copolymers were determined by thermal gravimetric analysis (Figure 8). It can be seen that the TG curve of cellulose shows a single decomposition stage with the onset decomposition temperature ( $\left.T_{\text {onset }}\right)$ at $310.29^{\circ} \mathrm{C}$, maximum decomposition temperature $\left(T_{\max }\right)$ at $375.83^{\circ} \mathrm{C}$. The cellulose- $g$-PCL copolymers show two decomposition stages, and the $T_{\text {onset }}$ and $T_{\max }\left(T_{\max 1}, T_{\max 2}\right)$ of cellulose- $g$-PCL copolymers are lower than cellulose at approximately 200,280

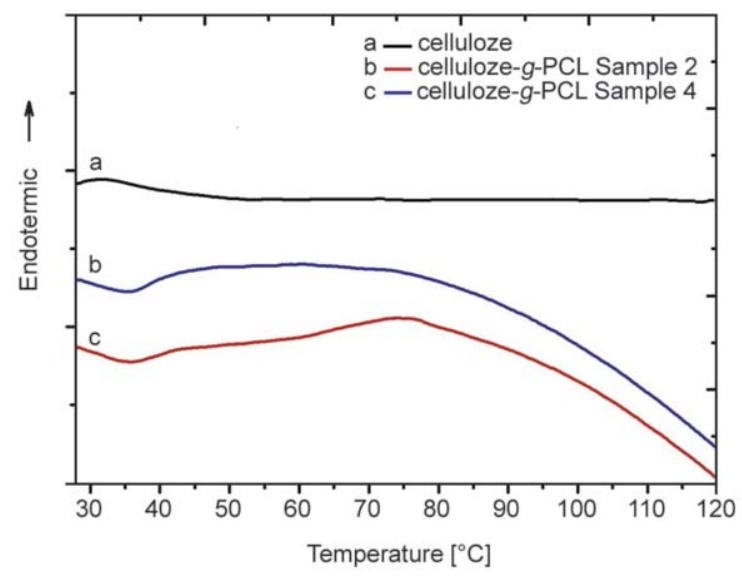

Figure 8. TG and DTG curves of cellulose (a), cellulose- $g$ PCL Sample 2 (b) and cellulose-g-PCL Sample 4 (c) and $360^{\circ} \mathrm{C}$ respectively. Obviously, the thermal stability of cellulose-g-PCL copolymers is not as good as that of cellulose.

$T_{\max 1}$ is ascribed to the PCL chain detached from cellulose backbone followed by the decomposition of the side chains, and $T_{\max 2}$ correspond to the decomposition of cellulose backbone. The lower $T_{\max 2}$ of graft copolymers compared with cellulose should be attributed to the reduction of hydrogen bonds and introduction of PCL side chains on the cellulose backbone, the crystalline structure of cellulose is broken partially. An evident decrease of weight by $5 \%$ due to loss of moisture between 50 and $100^{\circ} \mathrm{C}$ can be seen in the TG of cellulose and Sample 2, whereas there are no significant changes in Sample 4, because the DPPCL of Sample 5 is higher, so its hydroxyl group content is lower. As shown in Figure 8, the residue of the final cellulose is $10 \%$, the ultimate carbon residue of Sample 2 and Sample 4 are up to 26 and $27 \%$ respectively. This is mainly because the carbon content of $\varepsilon$-caprolactone $\left(\mathrm{C}_{6} \mathrm{H}_{10} \mathrm{O}_{2}\right)$ is higher than that of cellulose glucose $\left(\mathrm{C}_{6} \mathrm{H}_{10} \mathrm{O}_{5}\right)$. The experimental result confirms that the PCL introduced to the cellulose chain successfully.

The thermal behavior of cellulose-g-PCL copolymers was measured by DSC (Figure 9). No glass transition temperature $\left(T_{\mathrm{g}}\right)$ was detected for cellulose. Cellulose will be decomposed before reaching the melting temperature, because there is no sufficient temperature gap between that temperature sufficient to open the inter-molecular bond and that temperature at degradation of the entire material [34]. In Figure 9 , there is a $T_{\mathrm{g}}$ platform for cellulose- $g$-PCL copolymers at about $40^{\circ} \mathrm{C}$, and the DSC curves of

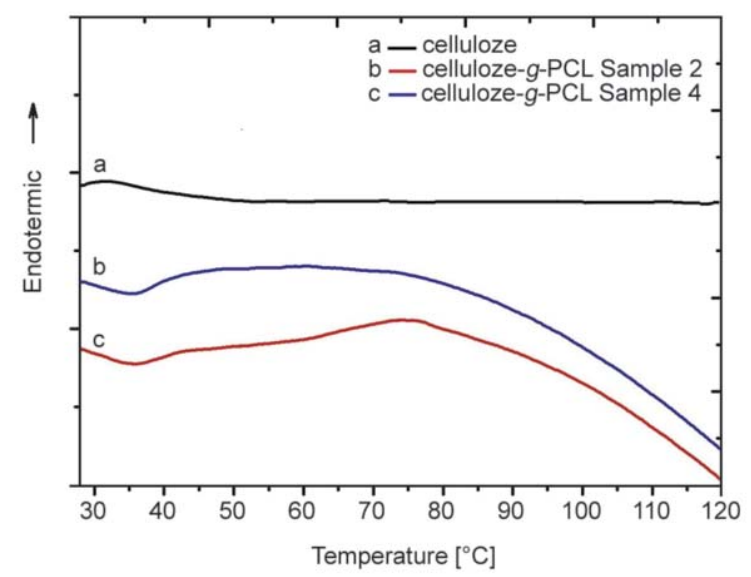

Figure 9. DSC curves of cellulose (a), cellulose- $g$-PCL Sample 2 (b) and cellulose-g-PCL Sample 4 (c) 
cellulose- $g$-PCL copolymers start to fell at about $80^{\circ} \mathrm{C}$ suggesting that the cellulose- $g$-PCL copolymers has become thermoplastic, the side chain PCL plays an effective role as internal plasticizer [20]. But there is no sharp endothermic peak, because intermolecular distance and chain mobility of cellulose increase after grafting amorphous PCL side chains.

\subsection{The remaining $\mathrm{Zn}$ and $\mathrm{Sn}$ species in the purified celluloseg-PCLs sample}

Since $\mathrm{Zn}$ can be strongly coordinated to cellulose $\mathrm{OH}$ groups, the remaining $\mathrm{Zn}$ and $\mathrm{Sn}$ species in the purified cellulose- $g$-PCL samples were analyzed by Inductively Coupled Plasma Optical Emission Spectrometry (ICP-OES).

The results showed that the weight percentage of $\mathrm{Zn}$ and $\mathrm{Sn}$ are 3.2 and $2.1 \%$ respectively. In the case of elemental $\mathrm{Zn}$, the amount of it in purified sample is low compared to the quality of $\mathrm{ZnCl}_{2}$ in the system before reaction. This illustrates the operation that the resultant polymer was precipitated by deionized water removed the overwhelming majority of $\mathrm{ZnCl}_{2}$. This is due to a large amount of water made the molar ratio of $\mathrm{Zn}^{2+}: \mathrm{H}_{2} \mathrm{O}$ got much lower than $1 / 4$, the activated orbits of $\mathrm{Zn}^{2+}$ were occupied by the extra water molecules, zinc chloride solution could not coordinate to cellulose $\mathrm{OH}$ groups. The existence of elemental Sn probably because a portion of $\mathrm{Sn}(\mathrm{Oct})_{2}$ was surrounded by the samples during the purification process.

\subsection{Mechanism analyses and aotential applications}

Based on above analyses and previous literatures, a sketch for three-dimensional structure of cellulose, a schematic of $\left[\mathrm{Zn}\left(\mathrm{H}_{2} \mathrm{O}\right)_{4}\right]^{2+}$ breaking hydrogen bonds in cellulose, mechanism scheme for cellulose-graftPCL copolymers synthesized via ROP in zinc chloride solution and a scheme of synthesis of cellulose derivatives with different side chain on diverse hydroxyl of AGU were given in Figure 10.

In Figure 10a, there are three kinds of hydrogen bonds in cellulose, which are $\mathrm{O}^{2} \mathrm{H} \cdots \mathrm{O}^{6}, \mathrm{O}^{3} \mathrm{H} \cdots \mathrm{O}^{5}$ (intra-chain) and $\mathrm{O}^{6} \mathrm{H} \cdots \mathrm{O}^{3}$ (inter-chain) $[1,3,26]$. Zinc chloride solution can break the intra-molecular hydrogen bonds of cellulose selectively, but has no effect on the intermolecular hydrogen bonds. $\left[\mathrm{Zn}\left(\mathrm{H}_{2} \mathrm{O}\right)_{4}\right]^{2+}$ accepts lone pair electrons on oxygen atom of $\mathrm{O}^{2} \mathrm{H}, \mathrm{O}^{6} \mathrm{H}, \mathrm{O}^{5}$, and $\mathrm{O}^{3} \mathrm{H}$, breaks the hydrogen bond of $\mathrm{O}^{2} \mathrm{H} \cdots \mathrm{O}^{6}$ or $\mathrm{O}^{3} \mathrm{H}^{\cdots} \mathrm{O}^{5}$, but does not destroy the hydrogen bond of $\mathrm{O}^{6} \mathrm{H}^{\cdots} \mathrm{O}^{3}$ (Figure $10 \mathrm{~b}$ ). Consequently solvent molecules $\left(\mathrm{H}_{2} \mathrm{O}\right)$ are able to penetrate in the network leading to cellulose dissolution. In Figure 10c, the catalyst $\mathrm{Sn}(\mathrm{Oct})_{2}$ is firstly attached to hydroxyl groups of $\mathrm{O}^{2} \mathrm{H}$ and $\mathrm{O}^{3} \mathrm{H}$ on cellulose via trans-alcoholysis reaction, then ROP of $\varepsilon-C L$ is initiated by coordination insertion of the $\mathrm{Sn}(\mathrm{Oct})_{2}$ on the monomer followed by the propagation step with $\varepsilon$-CL to form cellulose-g-PCL copolymer, where the hydroxyls on $\mathrm{C}^{2}$ and $\mathrm{C}^{3}$ are esterified eventually, however, the $\mathrm{C}^{6}-\mathrm{OH}$ groups have not been replaced, synthesis 2,3-di-O-PCL-cellulose successfully.

This is the reason why the reactivity of hydroxyl on cellulose is $\mathrm{C}^{2}-\mathrm{O}^{2} \mathrm{H}>\mathrm{C}^{3}-\mathrm{O}^{3} \mathrm{H} \gg \mathrm{C}^{6}-\mathrm{O}^{6} \mathrm{H}$ in zinc chloride solution. This conclusion is different from previous reports in that the reactivity of $\mathrm{C}^{6}-\mathrm{OH}$, farther away from AGU than secondary hydroxyls should be higher than $\mathrm{C}^{2}-\mathrm{OH}$ or $\mathrm{C}^{3}-\mathrm{OH}[31,32]$.

Inspired by the characteristic reaction of cellulose with $\varepsilon$-CL monomer in $68 \%$ zinc chloride solution, some special cellulose derivatives may be designed with different substituent side chains. For example, as shown in Figure 10d, utilizing zinc chloride solution to break the intra-molecular hydrogen bonds of cellulose selectively, $\mathrm{O}^{2} \mathrm{H}$ and $\mathrm{O}^{3} \mathrm{H}$ could be activated effectively. A derivative (I.) with side chain $A_{n}$ on $\mathrm{O}^{2} \mathrm{H}$ purely might be obtained by adjusting the molar ratio of monomer $\mathrm{A} / \mathrm{AGU}$ and reaction condition theoretically. Then derivative (II.) was synthesized through adding monomer $\mathrm{B}$ and changing reaction condition. Finally, if another dissolution reaction system, such as ionic liquids or $\mathrm{LiCl} / \mathrm{DMA}$, was used to interrupt the hydrogen bond of $\mathrm{O}^{6} \mathrm{H}^{\cdots} \mathrm{O}^{3}$ in derivative (II.) and monomer $\mathrm{C}$ was adopted, the derivative (III.) together with side chains of $A_{n}, B_{n}$ and $C_{n}$ on given hydroxyl of cellulose might be obtained. This hypothesis is interesting and exciting, the method is new and special. The cellulose derivatives with different groups have a good chance in many fields such as medicine, food packaging, polymer chemistry and polymer processing and so on [22, 23, 35, 36]. So, the further work will be focused on above feasibility to synthesize functional cellulose derivatives.

\section{Conclusions}

In the present work, a convenient and efficient regiocontrolled synthesis of cellulose- $g$-PCL copolymers (2,3-di-O-PCL-cellulose ) was conducted successfully by ROP graft reaction of cellulose with 

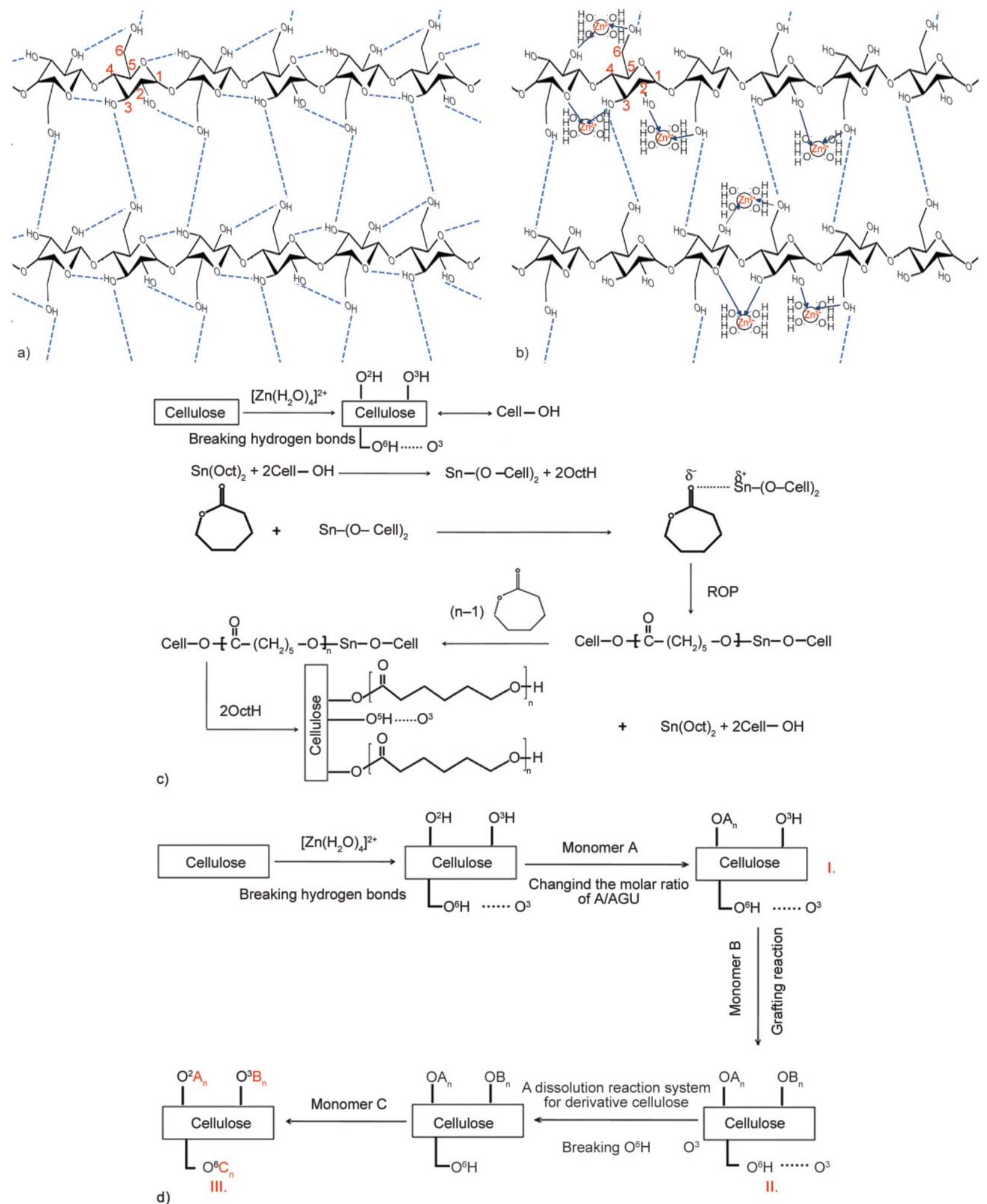

Figure 10. Three-dimensional structure of cellulose (a), schematic of $\left[\mathrm{Zn}\left(\mathrm{H}_{2} \mathrm{O}\right)_{4}\right]^{2+}$ breaking hydrogen bonds (b), mechanism scheme for cellulose-graft-PCL copolymers synthesized via ROP in zinc chloride solution (c) and scheme of synthesis of cellulose derivatives with different side chain on diverse hydroxyl of AGU (d)

$\varepsilon$-CL using $\mathrm{Sn}(\mathrm{Oct})_{2}$ as an catalyst in $68 \%$ concentration of zinc chloride solution at $120^{\circ} \mathrm{C}$, for the first time. Zinc chloride solution could be used to synthesize cellulose-based derivative polymers. Thermal properties were studied by DSC, thermal stability was also evaluated by TGA. The resultant cellulose- $g$-PCL copolymers exhibited thermoplastic and thermal stabilities decreased after chemical modified. The construction of cellulose- $g$-PCL copolymers and crystalline structure characterized by FT-IR, 
${ }^{1} \mathrm{H}$ NMR and XRD. The results indicate that there exists primary hydroxyl $\mathrm{C}^{6}-\mathrm{O}^{6} \mathrm{H}$ in cellulose- $g$-PCL with secondary hydroxyl of $\mathrm{C}^{2}-\mathrm{O}^{2} \mathrm{H}$ and $\mathrm{C}^{3}-\mathrm{O}^{3} \mathrm{H}$ replaced by $\mathrm{PCL}$ partly or entirely, that is, grafting reaction mainly occurs on the secondary hydroxyl, $\varepsilon$-CL does not react with hydroxyl groups on $\mathrm{C}^{6}$. Crystalline structure of cellulose still exists in cellulose$g$-PCL copolymers. And the remaining $\mathrm{Zn}$ and $\mathrm{Sn}$ species in the purified cellulose- $g$-PCL samples were analyzed by ICP-OES. The results showed that the elemental have been removed mostly after being purified with solvent. Zinc chloride broke the intramolecular hydrogen bonds of cellulose $\left(\mathrm{O}^{2} \mathrm{H} \cdots \mathrm{O}^{6}\right.$, $\left.\mathrm{O}^{3} \mathrm{H}^{\cdots} \mathrm{O}^{5}\right)$ selectively, but has no effect on the intermolecular hydrogen bonds $\left(\mathrm{O}^{6} \mathrm{H} \cdots \mathrm{O}^{3}\right)$. And the reactivity of hydroxyl on cellulose is $\mathrm{C}^{2}-\mathrm{O}^{2} \mathrm{H}>\mathrm{C}^{3}-\mathrm{O}^{3} \mathrm{H}$ $\gg \mathrm{C}^{6}-\mathrm{O}^{6} \mathrm{H}$ in zinc chloride solution. Most importantly, this work confirmed that the method to regiocontrolled synthesis cellulose-based derivative polymers by regiobreaking hydrogen bonds is feasible.

It is strongly believed that the new discovery may give a novel, environmentally bening, simple and inexpensive method of chemically modified celluloses to graft various side chains on given hydroxyl of cellulose through liberating hydroxyl as reactive group from hydrogen bonds, selectively broken by different solvents.

\section{References}

[1] Klemm D., Heublein B., Fink H-P., Bohn A.: Cellulose: Fascinating biopolymer and sustainable raw material. Angewandte Chemie International Edition, 44, 33583393 (2005).

https://doi.org/10.1002/anie.200460587

[2] Abdul Khalil H. P. S., Bhat A. H., Ireana Yusra A. F.: Green composites from sustainable cellulose nanofibrils: A review. Carbohydrate Polymers, 87, 963-979 (2012).

https://doi.org/10.1016/j.carbpol.2011.08.078

[3] Krässig H., Schurz J., Steadman R. G., Schliefer K., Albrecht W.: Cellulose. in 'Ullmann's encyclopedia of industrial chemistry' (ed.: Elvers B.) Wiley, Weinheim (2000). https://doi.org/10.1002/14356007.a05 375

[4] Eichhorn S. J., Dufresne A., Aranguren M., Marcovich N. E., Capadona J. R., Rowan S. J., Weder C., Thielemans W., Roman M., Renneckar S., Gindl W., Veigel S., Keckes J., Yano H., Abe K., Nogi M., Nakagaito A. N., Mangalam A., Simonsen J., Benight A. S., Bismarck A., Berglund L. A., Peijs T.: Review: Current international research into cellulose nanofibres and nanocomposites. Journal of Materials Science, 45, 1-33 (2010).

https://doi.org/10.1007/s10853-009-3874-0
[5] Zhang G., Huang D., Hou X.: Research advance in grafting lactones to cellulose by ring-opening polymerization (in Chinese). Chemical Industry and Engineering Progress, 31, 144-150 (2012).

[6] Carlmark A., Larsson E., Malmström E.: Grafting of cellulose by ring-opening polymerisation - A review. European Polymer Journal, 48, 1646-1659 (2012).

https://doi.org/10.1016/j.eurpolymj.2012.06.013

[7] Petzold K., Klemm D., Stein A., Günther W.: Synthesis and NMR characterization of regiocontrolled starch alkyl ethers. Designed Monomers and Polymers, 5, 415-426 (2002).

https://doi.org/10.1163/156855502760408099

[8] Kondo T., Gray D. G.: The preparation of O-methyl- and O-ethyl-celluloses having controlled distribution of substituents. Carbohydrate Research, 220, 173-183 (1991). https://doi.org/10.1016/0008-6215(91)80015-F

[9] Kern H., Choi S., Wenz G., Heinrich J., Erhardt L., Mischnick P., Garidel P., Blume P.: Synthesis, control of substitution pattern and phase transitions of 2,3-di-o-methylcellulose. Carbohydrate Research, 326, 67-79 (2000). https://doi.org/10.1016/S0008-6215(00)00024-0

[10] Kamitakahara H., Koschella A., Mikawa Y., Nakatsubo F., Heinze T., Klemm D.: Syntheses and comparison of 2,6-di-o-methyl celluloses from natural and synthetic celluloses. Macromolecular Bioscience, 8, 690-700 (2008).

https://doi.org/10.1002/mabi.200700291

[11] Koschella A., Heinze T., Klemm D.: First synthesis of 3-O-functionalized cellulose ethers via 2,6-di-O-protected silyl cellulose. Macromolecular Bioscience, 1, 49-54 (2001).

https://doi.org/10.1002/1616-5195(200101)1:1<49::AIDMABI49>3.0.CO;2-C

[12] Kondo T.: The relationship between intramolecular hydrogen bonds and certain physical properties of regioselectively substituted cellulose derivatives. Journal of Polymer Science Part B: Polymer Physics, 35, 717-723 (1997).

https://doi.org/10.1002/(SICI)1099-

0488(199703)35:4<717::AID-POLB18>3.0.CO;2-J

[13] Hiroshi K.: Regiocontrolled synthesis of cellulose derivatives and their functions (in Japanese). Mokuzai Gakkaishi, 60, 144-168 (2014). https://doi.org/10.2488/jwrs.60.144

[14] Zhen L., Zhang G., Huang K., Ren X., Li R., Huang D.: Modification of rice straw for good thermoplasticity via graft copolymerization of $\varepsilon$-caprolactone onto acetylated rice straw using ultrasonic-microwave coassisted technology. ACS Sustainable Chemistry and Engineering, 4, 957-964 (2016).

https://doi.org/10.1021/acssuschemeng.5b01039

[15] Liebert T.: Cellulose solvents - Remarkable history, bright future. in 'Cellulose solvents: For analysis, shaping and chemical modification' (eds.: Liebert T. F., Heinze T. J., Edgar K. J.) ACS Symosyum Series, Vol. 1033, 3-54 (2008).

https://doi.org/10.1021/bk-2010-1033.ch001 
[16] Medronho B., Lindman B.: Competing forces during cellulose dissolution: From solvents to mechanisms. Current Opinion in Colloid and Interface Science, 19, 32-40 (2014).

https://doi.org/10.1016/j.cocis.2013.12.001

[17] Hermanutz F., Gähr F., Uerdingen E., Meister F., Kosan B.: New developments in dissolving and processing of cellulose in ionic liquids. Macromolecular Symposium, 262, 23-27 (2008).

https://doi.org/10.1002/masy.200850203

[18] Spörl J. M., Ota A., Son S., Massonne K., Hermanutz F., Buchmeiser M. R.: Carbon fibers prepared from ionic liquid-derived cellulose precursors. Materials Today Communications, 7, 1-10 (2016). https://doi.org/10.1016/j.mtcomm.2016.02.002

[19] Zhu C., Richardson R. M., Potter K. D., Koutsomitopoulou A. F., van Duijneveldt J. S., Vincent S. R., Wanasekara N. D., Eichhorn S. J., Rahatekar S. S.: High modulus regenerated cellulose fibers spun from a low molecular weight microcrystalline cellulose solution. ACS Sustainable Chemistry and Engineering, 4, 45454553 (2016).

https://doi.org/10.1021/acssuschemeng.6b00555

[20] Yan C., Zhang J., Lv Y., Yu J., Wu J., Zhang J., He J.: Thermoplastic cellulose-graft-poly(L-lactide) copolymers homogeneously synthesized in an ionic liquid with 4-dimethylaminopyridine catalyst. Biomacromolecules, 10, 2013-2018 (2009).

https://doi.org/10.1021/bm900447u

[21] Lee S. J., Lee H. S., Jeong S. W., Kim H-C., Lee S. G., Oh T. H.: Effect of dimethyl sulfoxide on synthesis of thermoplastic cellulose-graft-poly(L-lactide) copolymer using ionic liquid as reaction media. Journal of Applied Polymer Science, 132, 41331/1-41331/7 (2015). https://doi.org/10.1002/app.41331

[22] Guo Y., Wang X., Shen Z., Shu X., Sun R.: Preparation of cellulose-graft-poly( $\varepsilon$-caprolactone) nanomicelles by homogeneous ROP in ionic liquid. Carbohydrate Polymers, 92, 77-83 (2013).

https://doi.org/10.1016/j.carbpol.2012.09.058

[23] Ge W., Guo Y., Zhong H., Wang X., Sun R.: Synthesis, characterization, and micellar behaviors of hydroxyethyl cellulose-graft-poly(lactide/ $\varepsilon$-caprolactone/pdioxanone). Cellulose, 22, 2365-2374 (2015).

https://doi.org/10.1007/s10570-015-0663-6

[24] Goffin A-L., Raquez J-M., Duquesne E., Siqueira G., Habibi Y., Dufresne A., Dubois P.: From interfacial ringopening polymerization to melt processing of cellulose nanowhisker-filled polylactide-based nanocomposites. Biomacromolecules, 12, 2456-2465 (2011). https://doi.org/10.1021/bm200581h

[25] Yan C., Wu J., Zhang J., He J., Zhang J.: Hydrolytic degradation of cellulose-graft-poly(L-lactide) copolymers. Polymer Degradation and Stability, 118, 130-136 (2015).

https://doi.org/10.1016/j.polymdegradstab.2015.04.019
[26] Xu Q., Chen C., Rosswurm K., Yao T., Janaswamy S.: A facile route to prepare cellulose-based films. Carbohydrate Polymers, 149, 274-281 (2016). https://doi.org/10.1016/j.carbpol.2016.04.114

[27] Lu X., Shen X.: Solubility of bacteria cellulose in zinc chloride aqueous solutions. Carbohydrate Polymers, 86, 239-244 (2011).

https://doi.org/10.1016/j.carbpol.2011.04.042

[28] Jian X., Jun Y., Zhao X-F.: Solubility of cellulose in $\mathrm{ZnCl}_{2}$ aqueous solution and structure of regenerated cellulose (in Chinese). Journal of South China University of Technology, 38, 23-27 (2010).

https://doi.org/10.3969/j.issn.1000-565X.2010.02.005

[29] Jiang C., Wang X., Sun P., Yang C.: Synthesis and solution behavior of poly( $\varepsilon$-caprolactone) grafted hydroxyethyl cellulose copolymers. International Journal of Biological Macromolecules, 48, 210-214 (2011). https://doi.org/10.1016/j.ijbiomac.2010.11.007

[30] Dong H., Xu Q., Li Y., Mo S., Cai S., Liu L.: The synthesis of biodegradable graft copolymer cellulose-graftpoly(L-lactide) and the study of its controlled drug release. Colloids and Surfaces B: Biointerfaces, 66, 2633 (2008).

https://doi.org/10.1016/j.colsurfb.2008.05.007

[31] Wu J., Zhang J., Zhang H., He J., Ren Q., Guo M.: Homogeneous acetylation of cellulose in a new ionic liquid. Biomacromolecules, 5, 266-268 (2004).

https://doi.org/10.1021/bm034398d

[32] Takaragi A., Minoda M., Miyamoto T., Liu H. Q., Zhang L. N.: Reaction characteristics of cellulose in the $\mathrm{LiCl} /$ 1,3-dimethyl-2-imidazolidinone solvent system. Cellulose, 6, 93-102 (1999). https://oi.org/10.1023/A:1009208417954

[33] Park S., Baker J. O., Himmel M. E., Parilla P. A., Johnson D. K.: Cellulose crystallinity index: Measurement techniques and their impact on interpreting cellulase performance. Biotechnology for Biofuels, 3, 10/1-10/10 (2010). https://doi.org/10.1186/1754-6834-3-10

[34] Zhang G., Huang K., Jiang X., Huang D., Yang Y.: Acetylation of rice straw for thermoplastic applications. Carbohydrate Polymers, 96, 218-226 (2013). https://doi.org/10.1016/j.carbpol.2013.03.069

[35] Mincheva R., Jasmani L., Josse T., Paint Y., Raquez J-M., Gerbaux P., Eyley S., Thielemans W., Dubois P.: Binary mixed homopolymer brushes tethered to cellulose nanocrystals: A step towards compatibilized polyester blends. Biomacromolecules, 17, 3048-3059 (2016). https://doi.org/10.1021/acs.biomac.6b00932

[36] Li K., Huang J., Gao H., Zhong Y., Cao X., Chen Y., Zhang L., Cai J.: Reinforced mechanical properties and tunable biodegradability in nanoporous cellulose gels: Poly(L-lactide-co-caprolactone) nanocomposites. Biomacromolecules, 17, 1506-1515 (2016). https://doi.org/10.1021/acs.biomac.6b00109 